GHANA JOURNAL OF DEPARTMENT OF HEALTH, PHYSICAL EDUCATION AND RECREATION, SPORTS AND DANCE (GJOHPERSD)

\author{
Volume 9, Year 2016
}

A JOURNAL OF THE DEPARTMENT OF HEALTH, PHYSICAL EDUCATION AND RECREATION (HPER)

UNIVERSITY OF CAPE COAST

GHANA, WEST AFRICA 


\title{
A COMPARISON OF PATTERNS OF SPORTS INJURY BETWEEN ELITE PLAYERS OF BEACH SOCCER AND ASSOCIATION FOOTBALL IN NIGERIA
}

\author{
Tony Dansu \\ Department of Human Kinetics, Sports \& Health Education \\ Lagos State University, Lagos State Nigeria \\ Phone: +2348023921081 \\ Email: mauttin@yahoo.com
}

\begin{abstract}
It is the dream of every nation, and its athletes to excel in all sport competitions and tournaments, so as to maximise the benefits of success associated to excellence in performance. However, injury is a major factor militating against success of athletes; it is considered as a potential threat in sports. This study was a retrospective one, designed to compare the patterns of sports injury between a group of elite players of beach soccer and their counterparts of association football in Nigeria. For this purpose, 46 players (23 from each sport) were purposively selected to participate in the study. A self developed questionnaire titled Questionnaire on sports Injury among athletes (QSIA) with 0.78 reliability level was used for data collection, and the data collected were analysed using frequency, simple percentage, mean and independent t-test. Results showed that there are variations in the pattern of sports injuries sustained by beach soccer players and association footballers. These variations are noticeable in the types of sports injuries they sustained, the regions of the body affected by the injuries, the preceding incidents to the injuries, and the levels of intensity of the injuries.
\end{abstract}

Key Words: Association Football, Beach Soccer, Sports Injury, Intensity, Elite Players. 
A comparison of patterns of sports injury between elite players of beach soccer and Association Football in Nigeria

\section{Introduction}

Sport in the contemporary society is more than small business, as it has wide range of benefits accrues to it beyond the individuals who participate. According to Kumar (2014), beyond health and social benefits of sports to individuals, the education and economic impact that sport has on nations are unquantifiable. It is the dream of every nation, and its athletes to excel in all sport competitions and tournaments, so as to maximise the benefits of success associated to excellence in performance. However, injury is a major factor militating against success of athletes; it is considered as a potential threat in sports (Haghighi, et al, 2012). Sports represent an important source of injury that often leads to impairment in physical and social activities (Michard, Renaud \& Narring, 2001). According to Pray and Pray (2004), sports cause up to seven million injuries among Americans; with the highest incidence of such injury in children who are within the age-range of 5 to 15 years, having 59.3 injuries per 1,000; compared to 25.9 injuries per 1,000 in the general population. Also adolescents and young adults within the age range of 15 to 24 years recorded 56.4 per 1,000 incidences of injury.

There is a wider range of studies into sports injury carried out on association football when compare to beach soccer. Association football, among all sports has been reported to have recorded the highest percentage of sports injury at any point in time (FIFA Medical Assessment and Research Centre F-MARC, 2006; Medical News Today, 2005; Turner, Barlow \& Healthcote-Elliott, 2000; Egwu, Uche-Nwachi \& Adeniran, 1994; Adelekan, 1991 and Onifade, Agbojinmi \& Ososanya, 1991). There is relatively dearth of sports injury report on beach soccer, especially in Nigeria.

Beach soccer is a branch of association football that has gained popularity among countries. According to Beach Soccer Worldwide (BSW, 2015), it is the most popular sport on sand across the globe. Though not as popular as the association football, but very exciting due to its beautiful acrobatic moves that make it a high-impact, and attractive (Haghighi, Zamanian \& Zameni, 2012). History has it that beach soccer started in Brazil in the 1930s; originally then, it was conceived as a different form of soccer 
played on a sand surface, with the main purpose of maintaining the trained players' technical skills during the summer break (Rosario et al, 2015).

Obviously, over the years, beach soccer increased its popularity worldwide, and it is played in different formats. According to Rosario et al (2015), USA hosted the first professional international competition in Miami (Florida, USA) in 1993. Thereafter, beach soccer has become a truly global sport, as evidenced by the participation of teams, coming from 16 countries of the world, in the 2009 FIFA Beach Soccer World Cup (Dubai, United Arab Emirates). In Africa, the CAF Beach Soccer Championship is the main international championship for beach soccer, mirroring that of the African Cup of Nations in association football. Wikipedia (2015) states that this championship is also known as the FIFA Beach Soccer World Cup qualifiers for CAF; the championship was established in 2006 after FIFA made requirements for all confederations to begin holding a qualification tournament to determine the best national team(s) in the region and hence those who would proceed to represent their continent in the World Cup. This is a clear indication of acceptability and popularity of the sport all over the world, including Africa, and Nigeria to be specific.

Various epidemiological studies revealed a large number of sports injuries across various sports globally (Turner, Barlow \& Healthcote-Elliott, 2000; Egwu, Uche-Nwachi \& Adeniran, 1994). Injury is an unwanted phenomenon whose occurrence lowers efficiency. Injury gives rise to pain, loss of function and deformity. Immobilization leads to decreased in strength of ligaments and muscles. The overall result of this is reduction in the performance of the sportsmen and women (Kellett, 2003). A sports injury is the result of a complex interaction of various risk factors in the course of time; and sportsmen are at increased risk of certain sportsrelated injuries, particularly those involving the knee. Participation in competitive sports sets high demands on the sportsman's physical skills. As a result, the injury frequency is rather high among sportsmen (Ivarsson, 2008). 
A comparison of patterns of sports injury between elite players of beach soccer and Association Football in Nigeria

The incidence of sports injury is not a new phenomenon. It is as old as sports itself, and as long as men compete with themselves in contact or non-contact sports, there is likely be one form of injury or another. Despite the risks involved, individuals continue to engage in sporting activities, because sports these days have gone commercial. Also, the spirit of patriotism makes sportsmen, trainers, managers and even spectators attach an exaggerated sense of importance to victory in international sports engagements. Sportsmen therefore literally put in all in terms of physical and mental strength; and in some cases, they do so unscrupulously, to achieve peak performance. Particularly for beach soccer, not only is running in sand physically taxing, it is also extremely dangerous. DelVecchio (2012) observes that limbs and joints flex in ways that they are not supposed to flex when players are running on an unstable surface such as sand; hence, high likelihood of occurrences of injuries.

Since injury in sports (to a large extent) is inevitable, and it has been recognized as constituting a threat to good performance, health and even lives of sportsmen, it is essential that the causes and the patterns of these injuries be identified as a vital step towards prevention of injury in sports. This study therefore sought to compare the pattern of sports injuries between a group of elite players of beach soccer and their counterparts of association football in Nigeria. The specific focus was to make comparison on:

i. $\quad$ the type of sports injury sustained by the players;

ii. the regions of the body affected by the sports injury sustained;

iii. the preceding incidents to the injuries; and

iv. the intensity of sports injury sustained.

\section{Methods}

Research Design

This is a retrospective study that compared data from two independent groups; therefore, the research design that was adopted for the purpose of this study is the ex-post-facto design. The design is appropriate because the population of the study is a naturally occurring group, and the study was interested in "after the fact" of sports injuries among the groups. 


\section{Participants}

The population of the study was elite players of beach soccer and association football in Nigeria. The beach soccer players that participated in this study were those who had at one time or the other represented states or the nation in national and international competitions, and the association football players had represented states at the national level. Out of these, 46 participants (23 for each sport) that were purposively selected for the study, 33 $(71.7 \%)$ of them were below the age of 30 years, while $13(28.3 \%)$ were above the age of 30 years.

\section{Instrumentation}

A self developed questionnaire titled Questionnaire on sports Injury among athletes [QSIA] was used for data collection in this study. The questionnaire has two sections. Section A sort information on demographic data of the participants, which include their gender, age, national/international experience and sports of participation. Section B dealt with data on types of sports injury sustained by the athletes, the regions of the body affected, preceding incidents to the injuries, and severity of the injury. Copies of the instrument were served to three experts in physical education and sports science for validity; the questionnaire was thereafter subjected to test-retest method of reliability test that gave $r$ value of 0.78 .

With the aid of three trained research assistants, copies of the validated questionnaire were administered to the participants who were association football players of this study during the $17^{\text {th }}$ National Sports Festival held (Garden City Games 2011) in PortHarcourt, Rivers State Nigeria. The participants were visited in their various venues of event, and the copies of questionnaire administered to them were retrieved immediately to avoid loss. The researcher personally contacted three of the beach soccer players who assisted in administering the questionnaire to their colleagues. Of the 60 copies that were administered, $71.7 \%$ were retrieved, and this is considered adequate for the study.

Data Analysis 
A comparison of patterns of sports injury between elite players of beach soccer and Association Football in Nigeria

The injuries sustained by the participants of this study were scored based on their severity as defined by Federation Internationale de Football Association (FIFA) Medical Assessment and Research Centre (F-MARC, 2006) and Union of European Football Association [UEFA] Consensus Discussion (Hagglund, Walden, Bahr, \& Ekstrnad, 2005). The cut-off points for the different categories of injury severity were then allotted points as follows:

$$
\begin{aligned}
& \checkmark \text { slight }(1-3 \text { days })=1 \text { point } \\
& \checkmark \text { minor }(4-7 \text { days })=2 \text { points } \\
& \checkmark \text { mild }(8-15 \text { days })=3 \text { points } \\
& \checkmark \text { moderate }(16-28 \text { days })=4 \text { points; and } \\
& \checkmark \quad \text { major }(\text { above } 28 \text { days })=5 \text { points. }
\end{aligned}
$$

Days in the brackets indicate number of days the injured players spent out of active participation.

Frequency of sports injury was also coded as:

$$
\begin{aligned}
& \checkmark \text { frequent }=1 \text { point } \\
& \checkmark \text { more frequent }=2 \text { points } \\
& \checkmark \text { most frequent }=3 \text { points }
\end{aligned}
$$

The data collected and coded for the purpose of this study were analysed using simple percentage, mean and independent t-test. Pictorial analytical tool of component bar chart was used to further describe the results, and inferences were made at 0.05 level of significance.

\section{Results}

Table 1: Mean and t-test results on types of sports injury sustained by athletes

\begin{tabular}{lllllllll}
\hline Injury & Sport & No & & $\begin{array}{c}\text { SD } \\
{[ \pm]}\end{array}$ & dif. & $\begin{array}{c}\text { t- } \\
\text { test }\end{array}$ & df & Sig. \\
\hline \multirow{3}{*}{ Fracture } & B. & 23 & 0.13 & 0.34 & & & & \\
& Soccer & & & & 0.61 & - & 44 & 0.20 \\
& A. & 23 & 0.74 & 1.13 & & 2.46 & & \\
& Football & & & & & & & \\
Sprain/Strain & $\begin{array}{l}\text { B. } \\
\text { Soccer }\end{array}$ & 23 & 1.47 & 0.99 & & & & \multirow{2}{*}{0.46} \\
& A. & 23 & 1.78 & 1.13 & & 0.98 & & \\
& Football & & & & & & & \\
Dislocation & B. & 23 & 1.26 & 0.96 & & & & \\
& Soccer & & & & 1.13 & - & 44 & 0.00 \\
& & & 6 & & & & &
\end{tabular}


Tony Dansu
A.

Football

B. $\quad 23 \quad 2.39 \quad 0.72$

Muscle Cramp

Soccer

A.

$23 \quad 1.44$

0.96

$3.86 \quad 44$

0.00

Contusion

Football

B. $\quad 23 \quad 2.74 \quad 0.45$

\begin{tabular}{llll} 
Soccer & & & \\
\hline A. & 23 & 1.44 & 0.95
\end{tabular}

$\begin{array}{llll}1.50 & 4.22 & 44 & 0.001\end{array}$

Football

The results presented in table 1 shows differences in the meanscore on types of sports injury sustained by players in the two groups of this study. The mean-score of beach soccer players $(0.13 \pm 0.34)$ was less than that of the association footballers $(0.74 \pm 1.13)$ for fracture, while the mean-scores were higher for beach soccer players in muscle cramp $(2.39 \pm 0.72)$ and contusion $(2.74 \pm 0.45)$ than their counterparts in association football who recorded a mean-score of $1.44 \pm 0.95$ each for both muscle cramp and contusion. There are significant variations between the two categories of players in dislocation ( $\mathrm{t}=-4.50 ; \alpha 0.00)$, muscle cramp $(\mathrm{t}=3.86 ; \alpha 0.00)$, and contusion $(\mathrm{t}=4.22 ; \alpha 0.001)$. Fracture $(\mathrm{t}=$ $2.46 ; \alpha 0.00)$, and sprain/strain $(\mathrm{t}=-0.98 ; \alpha 0.46)$ show no significant difference in the frequency of sports injury sustained by the players of the two categories.

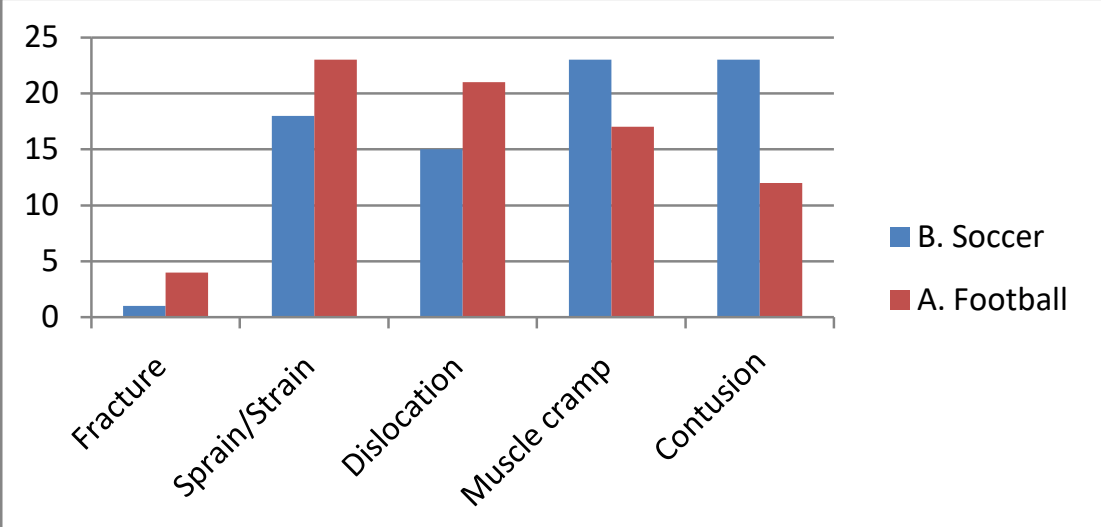

Figure 1: Component bar chart on types of sports injury sustained by players 
A comparison of patterns of sports injury between elite players of beach soccer and Association Football in Nigeria

Figure 1 descriptively compared the types of sports injury sustained by the players. It shows that fracture is the list sustained injury among the players, though it is more frequent among association footballers than the beach soccer players. Figure 1 further revealed that sprain, strain and dislocation are common to the two groups of players, but are higher in frequency among association footballers than beach soccer players. However, muscle cramp and contusion are more frequent among the beach soccer players than their counterpart in association football.

Table 2: Mean and t-test results on regions of the body affected by sports injuries

\begin{tabular}{|c|c|c|c|c|c|c|c|c|}
\hline Body Part & Sport & No & & $\begin{array}{l}\text { SD } \\
{[ \pm]}\end{array}$ & dif. & t-test & $\mathrm{df}$ & Sig. \\
\hline & B. Soccer & 23 & 0.48 & 0.73 & & & & \\
\hline \multirow[t]{2}{*}{ Head/Neck } & $\begin{array}{l}\text { A. } \\
\text { Football }\end{array}$ & 23 & 0.87 & 0.92 & 0.39 & -1.60 & 44 & 0.70 \\
\hline & B. Soccer & 23 & 0.22 & 0.60 & & & & \\
\hline \multirow[t]{2}{*}{ Trunk } & $\begin{array}{l}\text { A. } \\
\text { Football }\end{array}$ & 23 & 0.44 & 0.73 & 0.22 & -1.11 & 44 & 0.08 \\
\hline & B. Soccer & 23 & 0.48 & 0.67 & & & & \\
\hline \multirow[t]{2}{*}{ Arm/Finger } & $\begin{array}{l}\text { A. } \\
\text { Football }\end{array}$ & 23 & 0.78 & 0.80 & 0.30 & -1.41 & 44 & 0.34 \\
\hline & B. Soccer & 23 & 0.70 & 0.82 & & & & \\
\hline Knee & $\begin{array}{l}\text { A. } \\
\text { Football }\end{array}$ & 23 & 1.65 & 0.83 & 0.96 & 3.92 & 44 & 0.00 \\
\hline Ankle & $\begin{array}{l}\text { B. Soccer } \\
\text { A. } \\
\text { Football }\end{array}$ & $\begin{array}{l}23 \\
23\end{array}$ & $\begin{array}{l}1.65 \\
1.82\end{array}$ & $\begin{array}{l}0.65 \\
0.72\end{array}$ & 0.17 & 0.86 & 44 & 0.94 \\
\hline Chin & $\begin{array}{l}\text { B. Soccer } \\
\text { A. } \\
\text { Football }\end{array}$ & $\begin{array}{l}23 \\
23\end{array}$ & $\begin{array}{l}2.61 \\
0.78\end{array}$ & $\begin{array}{l}0.50 \\
0.74\end{array}$ & 1.83 & 9.85 & 44 & 0.001 \\
\hline Foot/Toe & $\begin{array}{l}\text { B. Soccer } \\
\text { A. } \\
\text { Football }\end{array}$ & $\begin{array}{l}23 \\
23\end{array}$ & $\begin{array}{l}2.87 \\
0.26\end{array}$ & $\begin{array}{l}0.34 \\
0.55\end{array}$ & 2.61 & 22.11 & 44 & 0.001 \\
\hline
\end{tabular}

The results presented in table 2 shows differences in the meanscore on body regions affected by sports injury sustained by players in the two groups of this study. The mean-score of beach soccer players $(0.70 \pm 0.82)$ was less than that of the association footballers $(1.65 \pm 0.83)$ for knee injury, while the mean-scores were higher for beach soccer players in chin $(2.61 \pm 0.50)$ and foot/toe $(2.87 \pm 0.34)$ than their counterparts in association football who recorded a mean-score of $0.78 \pm 0.74$ and $0.26 \pm 0.55$ for 
injuries to the chin and foot/toe respectively. Results in the table further shows no significant difference in the sports injuries that affected head and neck $(\mathrm{t}=-1.60 ; \alpha 0.70)$, trunk $(\mathrm{t}=-1.11 ; \alpha 0.08)$, arm and finger $(\mathrm{t}=-1.41 ; \alpha 0.34)$, and ankle $(\mathrm{t}=0.86 ; \alpha 0.94)$. However, it indicates significant difference in the sports injuries that affected knee $(\mathrm{t}=3.92 ; \alpha 0.00)$, Chin $(\mathrm{t}=9.85 ; \alpha 0.001)$, and Foot/toe ( $\mathrm{t}=22.11 ; \alpha 0.001)$.

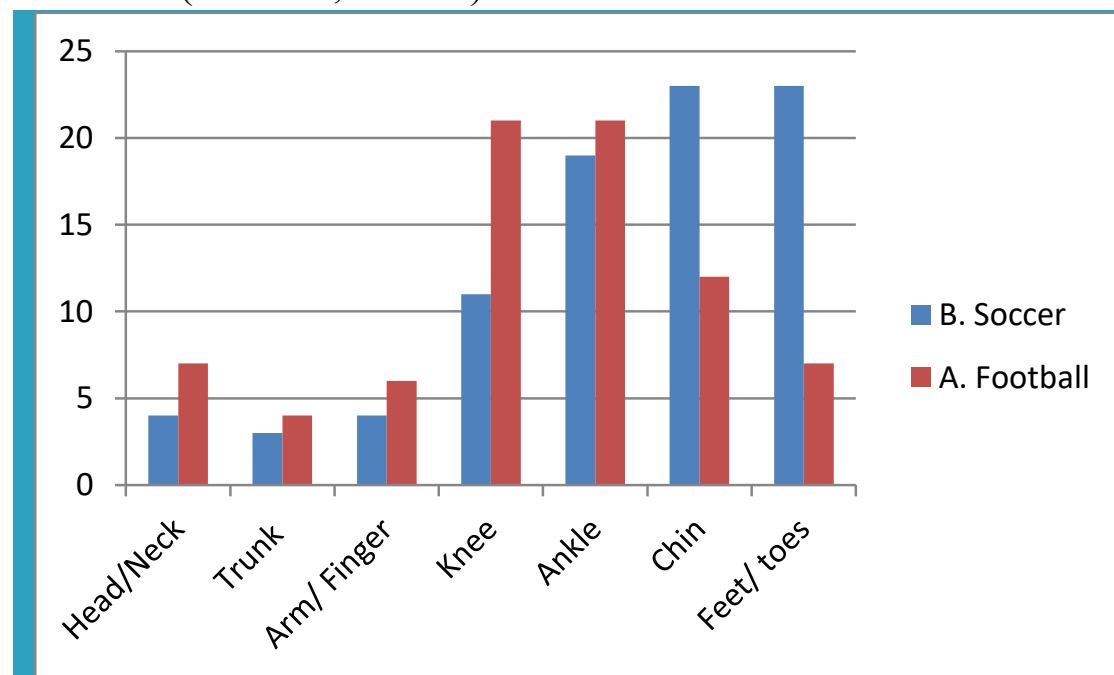

Figure 2: Component bar chart on body regions affected by sports injuries sustained by players

Comparing sports injuries sustained by the players in the two categories by body regions, figure 2 shows high frequencies of injuries for both groups at the knee, ankle, chin foot and toe. On another hand, the figure shows that beach soccer players frequently sustained injuries to the chin, foot and toe more than their counterparts in association football. But the association football players have higher frequency of sports injuries at the knee and ankle. 
A comparison of patterns of sports injury between elite players of beach soccer and Association Football in Nigeria

\begin{tabular}{|c|c|c|c|c|c|c|c|c|}
\hline Incident & Sport & No & & $\begin{array}{l}\text { SD } \\
{[ \pm]}\end{array}$ & dif. & t-test & $\mathrm{df}$ & Sig. \\
\hline \multirow{3}{*}{ Blocking/Tackling } & B. & 23 & 1.48 & 0.99 & \multirow{3}{*}{0.83} & \multirow{3}{*}{-3.16} & \multirow{3}{*}{44} & \multirow{3}{*}{0.003} \\
\hline & Soccer & & & & & & & \\
\hline & $\begin{array}{l}\text { A. } \\
\text { Football }\end{array}$ & 23 & 2.30 & 0.77 & & & & \\
\hline \multirow{3}{*}{ Shooting } & B. & 23 & 2.52 & 0.59 & \multirow{3}{*}{1.78} & \multirow{3}{*}{8.52} & \multirow{3}{*}{44} & \multirow{3}{*}{0.00} \\
\hline & Soccer & & & & & & & \\
\hline & A. & 23 & 0.74 & 0.81 & & & & \\
\hline \multirow{3}{*}{ Landing from Jump } & B. & 23 & 2.70 & 0.47 & \multirow{3}{*}{2.26} & \multirow{3}{*}{13.35} & \multirow{3}{*}{44} & \multirow{3}{*}{0.00} \\
\hline & Soccer & & & & & & & \\
\hline & $\begin{array}{l}\text { A. } \\
\text { Football }\end{array}$ & 23 & 0.44 & 0.66 & & & & \\
\hline \multirow{3}{*}{ Acrobatic Stunt } & B. & 23 & 2.83 & 0.39 & \multirow{3}{*}{2.26} & \multirow{3}{*}{14.13} & \multirow{3}{*}{44} & \multirow{3}{*}{0.00} \\
\hline & Soccer & & & & & & & \\
\hline & & 23 & 0.57 & 0.66 & & & & \\
\hline \multirow[t]{3}{*}{ Diving } & $\begin{array}{l}\text { Football } \\
\text { B. }\end{array}$ & 23 & 0.52 & 0.79 & \multirow{3}{*}{0.35} & \multirow{3}{*}{1.90} & \multirow{3}{*}{44} & \multirow{3}{*}{0.07} \\
\hline & Soccer & & & & & & & \\
\hline & $\begin{array}{l}\text { A. } \\
\text { Football }\end{array}$ & 23 & 0.17 & 0.39 & & & & \\
\hline
\end{tabular}

The results presented in table 3 shows differences in the meanscore of the two groups of players by the incident that preceded sports injury sustained by the players. The mean-score of beach soccer players $(1.48 \pm 0.99)$ was less than that of the association footballers $(2.30 \pm 0.77)$ for blocking and tackling, while the meanscores were higher for beach soccer players in landing from jump $(2.70 \pm 0.47)$ and acrobatic stunt $(2.83 \pm 0.39)$ than their counterparts in association football who recorded a mean-score of $0.44 \pm 0.66$ and $0.57 \pm 0.66$ for injuries sustained via landing from jumps and acrobatic stunts respectively. Results in the table shows no significant difference in the sports injuries sustained as a result of diving ( $\mathrm{t}=-1.90 ; \alpha 0.07)$, but there are significant variations in the sports injuries sustained via blocking and tackling $(\mathrm{t}=-3.16$; $\alpha 0.003)$, shooting ( $t=8.52 ; \alpha 0.00)$, landing from a jump $(t=13.35$; $\alpha 0.00)$ and acrobatic stunt $(\mathrm{t}=14.13 ; \alpha 0.00)$. 


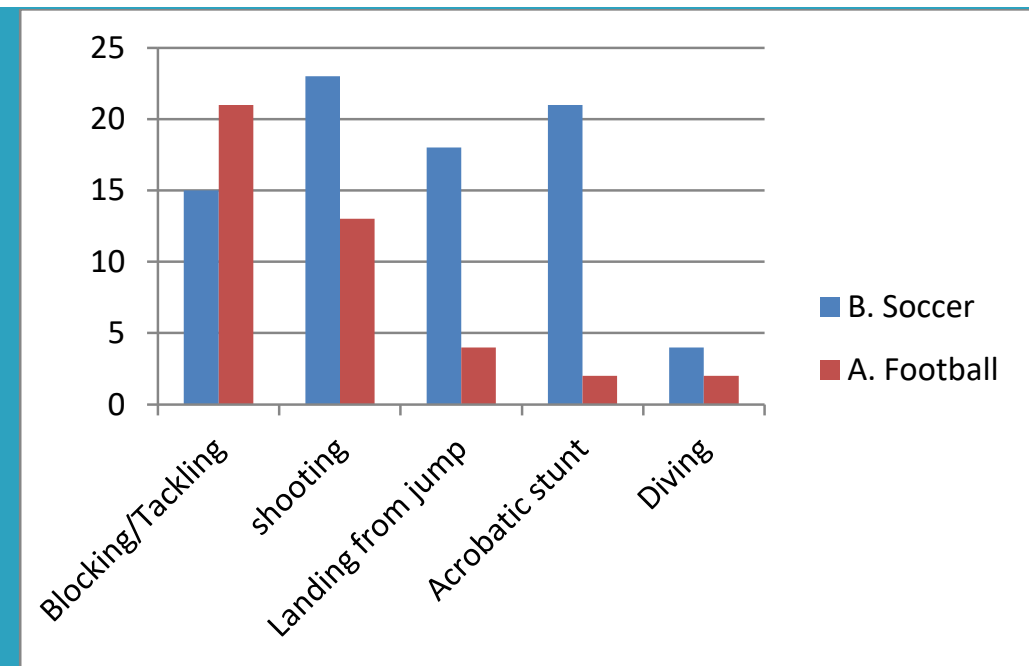

Figure 3: Component bar chart on preceding incidents to sports injuries sustained by players

Comparing sports injuries sustained by the players in the two categories by preceding incidents, figure 3 shows high frequencies of injuries for both groups in blocking and tackling, and shooting. Again, the figure shows that beach soccer players frequently sustained injuries via landing from jumps and acrobatic stunts more than their counterparts in association football. But the association football players have higher frequency of sports injuries via blocking and tackling.

Table 4: Mean and t-test results on intensity of sports injuries sustained by players

\begin{tabular}{rllllllll}
\hline \multicolumn{1}{r}{ Intensity } & \multicolumn{1}{c}{ Sport } & No & & $\begin{array}{r}\text { SD } \\
{[ \pm]}\end{array}$ & dif. & t-test & df & Sig. \\
\hline \multirow{3}{*}{ Slight } & B. Soccer & 23 & 2.74 & 0.45 & & & & \\
& A. & 23 & 2.61 & 0.50 & 0.13 & 0.93 & 44 & 0.08 \\
& Football & & & & & & & \\
Minor & B. Soccer & 23 & 2.44 & 0.59 & & & & \\
& A. & 23 & 2.35 & 0.65 & 0.09 & 0.48 & 44 & 0.64 \\
& Football & & & & & & & \\
Mild & B. Soccer & 23 & 2.09 & 1.20 & & & & \\
& A. & 23 & 2.22 & 1.08 & & & & \\
& Football & & & & & & &
\end{tabular}


A comparison of patterns of sports injury between elite players of beach soccer and Association Football in Nigeria

Moderate

B. Soccer

A. 23

1.87

0.87

Football

23

2.61

0.58

0.74

$-3.3$

B. Soccer

23

1.39

0.99

Major

\begin{tabular}{llll} 
A. & 23 & 2.26 & 0.69 \\
Football & & & \\
\hline
\end{tabular}

$\begin{array}{llll}0.87 & -3.46 \quad 44 & 0.01\end{array}$

The results presented in table 4 shows differences in the meanscore of the two groups of players by the intensity of sports injury sustained by the players. The mean-score of beach soccer players $(1.87 \pm 0.87$ and $1.39 \pm 0.99)$ were less than those of the association footballers $(2.61 \pm 0.58$ and $2.26 \pm 0.69)$ for moderate and major intensities of sports injuries respectively, while the mean-score was higher for beach soccer players in injuries with minor intensity $(2.44 \pm 0.59)$ than their counterparts in association football who recorded a mean-score of $2.35 \pm 0.65$ for injuries with minor intensity. Results in the table shows no significant difference in the sports injuries with, slight intensity $(\mathrm{t}=0.93 ; \alpha 0.08)$, minor intensity $(\mathrm{t}=-0.48 ; \alpha 0.64)$, and mild intensity $(\mathrm{t}=-0.13 ; \alpha 0.31)$, but there are significant variations in the sports injuries moderate intensity $(\mathrm{t}=-3.39 ; \alpha 0.02)$, and major intensity $(\mathrm{t}=-3.46 ; \alpha 0.01)$.

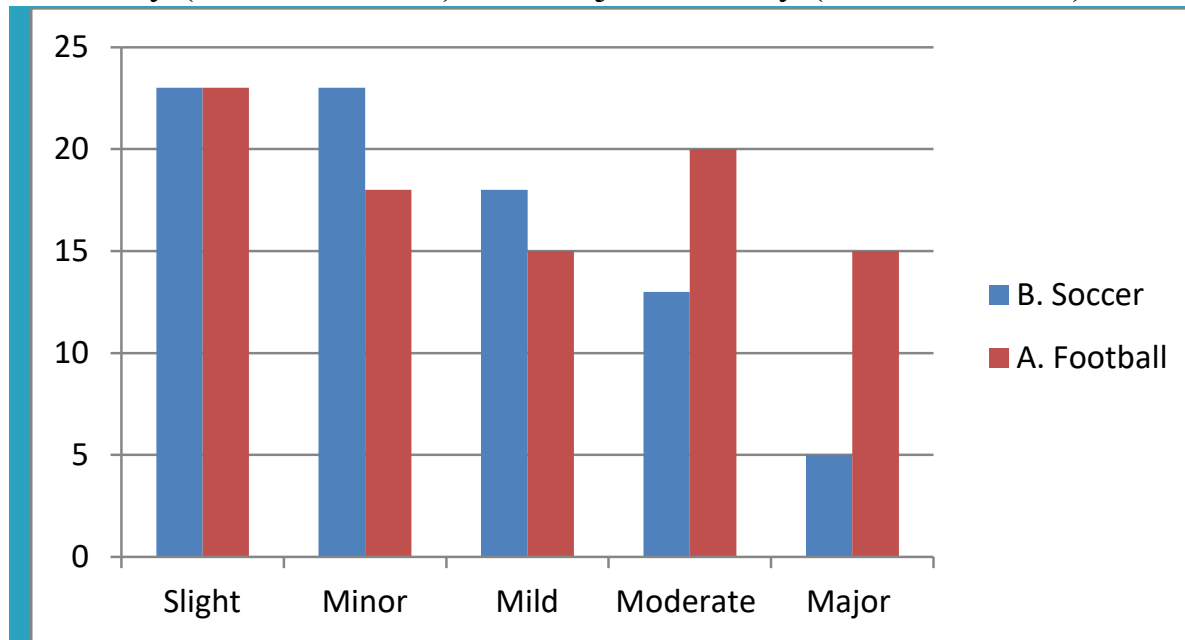

Figure 4: Component bar chart on intensity of sports injuries sustained by players 
Comparing sports injuries sustained by the players in the two categories by levels of intensity, figure 4 shows high frequencies of injuries for both groups in slight, minor, mild and moderate intensities. Again, the figure shows that beach soccer players frequently sustained minor injuries more than their counterparts in association football. But the association football players have higher frequency of moderate and major sports injuries than the beach soccer players.

\section{Discussion}

Results in this study show significant variations between the beach soccer players and association footballers in dislocation, muscle cramp, and contusion. In relation to fracture, sprain and strain there was no statistical significant difference in the frequency of sports injury sustained by the players of the two categories (see table 1). Results further show that sprain, strain and dislocation are common to the two groups of players, but are higher in frequency among association footballers than beach soccer players (see figure 1). This finding agrees with that of Dansu and Okuneye (2013) who reported sprain and strain scoring high percentage of sports injury among a group of association footballers. In a similar manner, Haghighi, et al (2012) reported high frequency of sprain among a group of beach soccer players.

Also, this study reveals that muscle cramp and contusion are more frequent among the beach soccer players than their counterpart in association football. This finding also tallies the report of Haghighi, et al (2012) that contusion recorded the highest form of injury among the beach soccer players in their study. According to Rosario et al (2015), in beach soccer it has been shown that running on sand surfaces is affected by the density and distribution of the sand (i.e. deep or easy moving sand), and determines a higher work load due to the increased work done by the lower extremity. This observation expressed on the playing surface, and the fact that it differs from that of association football may be a strong factor in the higher frequency of muscle cramp and contusion among the beach soccer players.

This study shows significant difference in the sports injuries as they affected knee, chin, and Foot/toe of the two groups of players 
A comparison of patterns of sports injury between elite players of beach soccer and Association Football in Nigeria

(see table 2). It reveals a higher frequency of knee injury among the association footballers, but higher frequency of injuries to the chin, foot and toe among the beach soccer players. However, ankle injury was high for both groups of players (see figure 2). This finding is in line with the report of Turner, Balow and HealthcoteElliott (2000) that the most common injuries in football are sprains and strains; affecting mainly the ankle and knee joints. According to Turner, Balow and Healthcote-Elliott (2000), knee injury, particularly crutiate ligaments (anterior-ACL and Posterior-PCL), accounted for nearly half (49\%) of all injury in enforced premature retirement from active football. Walker (2003) in a report also affirmed that ankle sprain is the commonest injury among professional football players; accounting for more than 1 in every 10 of total injury. Haghighi, et al (2012) in their study on beach soccer players reported foot, toes, chin and achill tendon as the commonest body regions affected by sports injury among the beach soccer players.

Considering preceding incidents to sports injury, this study shows significant variations in the injuries sustained via blocking and tackling, shooting, landing from a jump and acrobatic stunt. In this study also, the beach soccer players frequently sustained injuries via shooting, landing from jumps and acrobatic stunts more than their counterparts in association football. This is quite expected considering the nature of beach soccer. According to Haghighi, et al (2012), beach soccer is a sport that is associated with beautiful acrobatic moves which make it a high-impact game. Acrobatic moves are high risk initiatives that make players vulnerable to injuries. The fact that rules do not permit the use of shoes or any other foot protective materials may be responsible for injuries acquired via shooting.

This study shows no significant difference in the sports injuries with, slight, minor and mild intensities, but significant variations in injuries with moderate and major intensities. It further reveals that the beach soccer players frequently sustained more minor injuries and the association football players have higher frequency of moderate and major sports injuries (see table $4 \&$ figure 4 ). Dansu and Okuneye (2013) found a similar result in their study on a 
group of association footballers. They reported higher percentage of minor and mild severity levels of injury than slight and moderate levels. Jackson and Feagin (2013), in their study also found that 47 of 65 injuries recorded were mild, while 7 were moderate. Haghighi, et al (2012) are of the opinion that meticulous analysis of incidence of injuries and risk factors for health is the foundation of prevention plans. More so that it has thus been discussed as a necessity in medical congresses that athletes must become more familiar with the causes and mechanisms of injuries; especially young athletes who are more prone to injuries due to their physical, motor, and psychological characteristics.

\section{Conclusions and Recommendations}

Based on the findings of this study, it is concluded that there are variations in the pattern of sports injuries sustained by beach soccer players and association footballers. These variations are noticeable in the types of sports injuries they sustained, the regions of the body affected by the injuries, the preceding incidents to the injuries, and the levels of intensity of the injuries. Therefore, it is recommended that issue of injury prevention among the players of both sports should be given special attention. Players should be should be educated in both theory and practice, on strategies to prevent sports injury. Also, rules of beach soccer should be critically looked into with the aim of reviewing it to accommodate inclusion and/or modification of acceptable protective materials for the players, as this will further reduce the incidence of sports injury among the players without loss of the beauty and uniqueness of the game. 
A comparison of patterns of sports injury between elite players of beach soccer and Association Football in Nigeria

\section{References}

Adelekan, T. A. (1991). Injury at the NATCEGA '90 Games. Sports Science and Medicine, 1, 301-308.

Beach Soccer Worldwide (BSW, 2015). Beach Soccer among most popular sports in European Games. Retrieved from http://www.beachsoccer.com 02/12/2015

Dansu, A. \& Okuneye,R.O. (2013). A prospective study of sports injury among students of football academy in Nigeria. Proceedings of $55^{\text {th }}$ International Council for Health, Physical Education, Recreation sports and Dance (ICHPERSD) Anniversary World Congress 215-224.

DelVecchio, S. (2012). Beach soccer player suffers one of the nastiest knee injuries ever. Retrieved from http://larrybrownsports.com. 02/12/2015.

Egwu, M. O. (1996). The muscular skeletal effect of intense physical training of non-athletic youth corps conscripts. British Journal of Sports Medicine, 130, 11-115.

FIFA Medical Assessment and Research Centre (F-MARC, 2006) FIFA sets new definitions and procedures for injury in football (online). Retrieved from http://www.medicalnewstoday.com 14/02/08.

Hagglund, M. Walden, M. Bahr R \& Ekstrand, J. (2005). Methods for epidemiological study of injury to professional football players: Developing the UEFA model. British Journal of Sports Medicine, 39, 340-346.

Haghighi, M., Zamanian, F. \& Zameni, L. (2012). Incidence and mechanisms of injuries in female beach soccer players. Annals of Biological Research, 3 (7):3508-3512.

Ivarsson, A. (2008). Psychological predictors of sport injury among football players. Sports Psychology, 91-120.

Jackson, D.W. \& Feagin, J.A. (2013). Quadriceps contuisions in young athletes: Relation of severity of injury to treatment and prognosis. The Journal of Bones and Joint Surgery, 55(1), 95-105.

Kellett J. (2003). Acute soft tissue Injury - a review of literature. Journal of Medicine in Sports and Exercise, 28, 489-499. 
Kumar, R. (2014). The economic benefits of promoting sports. Retrieved from http//www.ndtv.com 02/12/2015.

Medical News Today (2005): Football (Soccer) Players are sportsmen most at risk of injury (online). Retrieved from http://www.medicalnewstoday.com. 14/02/08.

Michard, P. A., Renaud, A., \& Narring, F. (2001). Sports activities related to injury? A survey among 9-19 year olds in Switzerland. Injury Prevention, 7, 41-45.

Onifade, A., Agbonjinmi, A., \& Ososanya, D. (1991). Sports injury among University athletes. Sports Science and Medicine, 1, 255-262.

Pray, W. S. \& Pray, J. J. (2004). Prevalence of sports injury and epidemiology (online). Retrieved from http://www.medscrape.com. 12/02/08.

Rosario S., Carlo M., Antonio A., Laura C. and Antonio T. (2015). Match analysis and heart rate of beach soccer players during amateur competition. Graduate Journal of Sport, Exercise \& Physical Education Research, 3, 1-12.

Turner, A. P., Barlow, J. H. \& Healthcote-Elliott, C. (2000). Long term health impact of playing professional football in the United Kingdom. The British Journal of Sports Medicine, 34, 332-336.

Walker, I. (2003). Football injury - Ankle sprains: the bane of football players British Journal of Medicine, 37, 233-238.

Wikipedia (2015). CAF Beach Soccer Championship. Retrieved from https://en.wikipedia.org. 02/12/2015. 